\title{
Glutamine depletion impairs cellular stress response in human leucocytes
}

\author{
Rudolf Oehler*, Erich Pusch, Peter Dungel, Maria Zellner, Maja Munk Eliasen, \\ Marianne Brabec and Erich Roth \\ Surgical Research Laboratories, University of Vienna, A-1090 Vienna, Austria
}

\begin{abstract}
During sepsis and major trauma the blood glutamine (Gln) level is reduced. The administration of Gln can improve the outcome of these patients. However, the mechanism of this beneficial effect of Gln is poorly understood. In the course of critical illness leucocytes are confronted with cytotoxic inflammatory mediators. To protect themselves against these factors, cells express heat shock proteins (HSP). Previous studies have shown that the expression of the major inducible HSP (HSP70) is improved by high Gln concentrations above $4 \mathrm{mM}$. In this study we investigated whether Gln depletion, such as observed during critical illness, has an effect on HSP70 expression. Human lymphocytes exposed for $2 \mathrm{~h}$ to $42^{\circ} \mathrm{C}$ showed a 3 -fold increase in HSP70 expression $(P<0 \cdot 01)$. A preceding Gln starvation period over 3 days had no influence on this increase. However, when Gln is reduced during the stress response, HSP70 expression is impaired. A reduction of Gln from $0.5 \mathrm{mM}$ (physiological) to $0.125 \mathrm{mM}$ (pathological) led to a $40 \%$ lower HSP70 level $(P<0 \cdot 002)$. In contrast, increasing Gln concentrations (up to $2 \mathrm{mM}$ ) had only minor stimulatory effects (about $15 \%$ ). This Gln-dependency of heat mediated HSP70 expression was observed in resting as well as proliferating lymphocytes. Our data indicate that during periods of reduced plasma Gln levels the stress response of human lymphocytes is impaired. Thus, Gln may be essential to minimize the susceptibility of leucocytes to cytotoxic inflammatory mediators. This is a new aspect of the protective effect of Gln supplementation in critically ill patients.
\end{abstract}

Lymphocytes: Heat shock proteins: HSP70: Glutamine

\section{Introduction}

Glutamine (Gln) is the most abundant free amino acid in the blood and in the amino acid pool of the body. During starvation and catabolic stress after trauma, surgical procedures, or during sepsis and certain cancers, plasma Gln levels are strongly reduced. Several studies have demonstrated that Gln supplementation can provide an approach for modulation of severity of these critical diseases (for review see $\mathrm{Neu}$ et al. 1996). The mechanisms of the beneficial effects of Gln supplementation in critical illness remain poorly understood. The availability of Gln has been found to be especially important for survival and function of leucocytes. Gln deprivation decreases mitogen-inducible proliferation in lymphocytes (Szondy \& Newsholme, 1991) and increases susceptibility to apoptosis of premonocytic U937 cells (Petronini et al. 1996). In previous studies we could show that in the absence of Gln, expression of surface proteins responsible for antigen presentation and phagocytosis in human monocytes is down-regulated (Spittler et al. 1995) and differentiation of premonocytic U937 cells is induced (Spittler et al. 1997). Supplementation of Gln abolishes these effects.

In the course of critical illness leucocytes are exposed to huge amounts of cytotoxic inflammatory mediators such as reactive oxygen species. In order to protect themselves against these factors, leucocytes express a group of proteins which are essential to cellular survival under such stressful conditions, the heat shock proteins (HSPs) (Polla \& Cossarizza, 1996; Welch, 1991). HSP can be divided into several families according to their molecular weight. The $70 \mathrm{kDa}$ heat shock protein (HSP70) has attracted the most interest because it exhibits the strongest protective effect against environmental insults including heat, UVirradiation, heavy metals and reactive oxygen species. Induction of HSP70 was found to increase survival of mice in an endotoxin-induced sepsis model (Ribeiro et al. 1994; Villar et al. 1994) and in a respiratory distress syndrome model (Villar et al. 1993). In addition, overexpression of

\footnotetext{
Abbreviations: Gln, glutamine; HSP, heat shock protein.

* Corresponding author: Dr Rudolf Oehler, Surgical Research Laboratories, AKH (8G9.05), Waehringer Guertel 18-20, A-1090 Vienna, Austria, fax +43 1 40400 6782, email rudolf.oehler@akh-wien.ac.at
} 
HSP70 in a transgenic mouse model reduced the lethality after ischemia-reperfusion (Suzuki et al. 1997). Thus, high expression of HSP70 protects each cell against toxic agents as well as the whole body against pathological insults.

There are some reports in the literature describing that Gln can affect HSP70 expression in various cell types. Cai et al. (1991) observed that the addition of fresh medium to Chinese hamster ovary (CHO) cells induced HSP70 expression. They identified Gln as the stimulating compound. In the absence of any stress, addition of Gln to cells led to an increase of HSP70 expression. Similarly, HSP70 expression could also be induced in rat intestinal crypt IEC-18 cells simply by adding Gln (Musch et al. 1998; Wischmeyer et al. 1997). In contrast, Gln increases HSP70 expression in Opossum kidney OK cells (Nissim et al. 1993) and in rat intestinal IEC-6 cells (Ehrenfried et al. 1995) only after heat treatment of cells. In all these studies the Gln concentrations needed to yield the maximum increase in HSP70 expression were rather high (CHO cells: $5 \mathrm{mmol} / \mathrm{l}$, IEC-18 cells: $20 \mathrm{mmol} / \mathrm{l}$, OK cells: $4 \mathrm{mmol} / \mathrm{l}$, IEC-6 cells: $8 \mathrm{mmol} / \mathrm{l}$ ) and far beyond physiological plasma levels $(0.5-0.7 \mathrm{mmol} / \mathrm{l})$. In the present study we investigated the influence of Gln reduction, similar to what is observed during critical illness, on HSP70 expression. Using human lymphocytes as a model system we could show that Glndepletion leads to a reduced HSP70 expression of heat stressed cells. This indicates that during periods of low plasma Gln levels, the stress response of leucocytes is impaired which makes these cells more susceptible to cytotoxic inflammatory mediators.

\section{Materials and methods}

\section{Lymphocyte isolation and treatment}

Lymphocytes were isolated from whole blood by density gradient centrifugation as has been previously described (Coligan et al. 1996). Briefly, heparinized whole blood was centrifuged through a FICOLL-PAQUE layer (from Amersham-Pharmacia, Buckinghamshire, UK). The resulting buffy coat, which consisted of lymphocytes and monocytes, was diluted in complete medium (RPMI-1640 supplemented with $10 \%$ fetal calf serum (FCS) and $2 \mathrm{mM}$ Gln) and placed in a plastic tissue culture flask for $3 \mathrm{~h}$. During this time monocytes adhere to the plastic surface and lymphocytes remain in suspension. Then lymphocytes were washed, diluted in complete medium to $10^{6}$ cells per $\mathrm{ml}$ and cultured for $72 \mathrm{~h}$ at $37^{\circ} \mathrm{C}$. For heat treatment lymphocytes were washed in PBS, diluted in the indicated medium to $10^{6}$ cell per $\mathrm{ml}$ and placed in a $42^{\circ} \mathrm{C}$ incubator. To allow HSP70 synthesis, lymphocytes were then placed into $37^{\circ} \mathrm{C}$ for $3 \mathrm{~h}$. This treatment induced neither apoptosis nor necrosis as determined by annexin- $\mathrm{V}$ assay.

\section{Flow cytometry}

Intracellular staining of HSP70 was performed according to Bachelet et al. 1998 with modifications. Briefly, $100 \mu \mathrm{l}$ heparinized whole blood was mixed with $5 \mathrm{ml}$ lysis solution $\left(155 \mathrm{mM} \mathrm{NH}_{4} \mathrm{Cl}, 10 \mathrm{mM} \mathrm{KHCO}_{3} \mathrm{pH}=7 \cdot 4\right.$, and $0 \cdot 1 \mathrm{mM}$ EDTA) and incubated for $10 \mathrm{~min}$ at room temperature for elimination of erythrocytes. The remaining leucocytes were washed at $4^{\circ} \mathrm{C}$ in HBSS (Bio-Whittaker, Verviers, Belgium) containing $3 \%$ FCS, suspended in $250 \mu$ l fixation solution containing paraformaldehyde (Cytofix/Cytoperm Plus Kit from BD-Pharmingen, San Jose, CA, USA) and incubated for $15 \mathrm{~min}$ at $4^{\circ} \mathrm{C}$ for fixation. Cells were then centrifuged for 5 minutes at $600 \mathrm{~g}$, suspended in $100 \mu \mathrm{l}$ of a 1:300 dilution of a HSP70 specific antibody (SPA810 from Stressgen, Victoria, Canada) in permeabilization solution containing saponin (Cytofix/Cytoperm Plus Kit) and incubated for $30 \mathrm{~min}$ at $4^{\circ} \mathrm{C}$. After washing in permeabilization solution cells were incubated in a 1:250 dilution of FITC-labeled anti-mouse IgG1 antibody (BD-Pharmingen, San Jose, CA, USA) for $30 \mathrm{~min}$ at $4^{\circ} \mathrm{C}$ and washed again in permeabilization solution. Negative control staining was performed with appropriate fluorescence labeled isotype IgG antibodies (Immunotech, Marseilles, France). The results obtained with controls were subtracted from the specific signal. Stained cells were analyzed using a flow cytometer (Epics XL, Coulter, Miami, FL, USA). 10000 events were acquired.

\section{Results \\ Heat treatment of cultured lymphocytes induces HSP7O expression}

HSP70 is induced by heat stress in almost all organisms, but the level of induction depends on the temperature as well as on the responding cell type. To investigate the influence of heat stress on HSP70 expression in human lymphocytes we exposed these cells to a heat shock $\left(42^{\circ} \mathrm{C}\right.$ for $\left.2 \mathrm{~h}\right)$ and measured HSP70 expression by flow cytometry. The results are shown in Fig. 1A. Untreated cells showed a weak HSP70 expression. Heat treatment, however, led to a strong increase in fluorescence signal indicating enhanced HSP70 expression. The evaluation of the histograms, using the specific mean fluorescence intensity (MFI) as a measure for cellular HSP70 expression, revealed that in heat shocked lymphocytes HSP70 levels were about $200 \%$ of untreated controls (see Fig. 1B).

\section{Heat-mediated HSP70 expression depends on glutamine}

HSP70 expression is improved by high Gln concentrations in various animal cell lines. However, the effects of Gln depletion are largely unknown. To investigate the effect of long-term Gln starvation on HSP70 expression we cultured isolated lymphocytes for $72 \mathrm{~h}$ in Gln-free medium. These Gln-depleted cells were suspended in complete medium, exposed to heat shock, and after recovery at $37^{\circ} \mathrm{C}$ HSP70 expression was measured. As shown in Fig. 2A, a Gln starvation period of 3 days neither had an effect on the constitutive HSP70 expression nor on the heat-induced HSP70 expression.

For further characterization we investigated the stress response to heat shock while cells were incubated continuously in reduced Gln concentrations. For this purpose, we suspended isolated lymphocytes cultured in complete medium for $72 \mathrm{~h}$ in medium with different Gln concentrations $(0,62 \cdot 5,125,250,500,1000$, or $2000 \mu \mathrm{M}$ 
Gln) and exposed them to heat shock. Then cells were allowed to recover for $3 \mathrm{~h}$ at $37^{\circ} \mathrm{C}$, and HSP70 expression was analyzed. Cells treated with the same conditions but kept at $37^{\circ} \mathrm{C}$ were used as negative controls. We found that the varying Gln concentration in the medium had no effect on the constitutive HSP70 expression (data not shown).

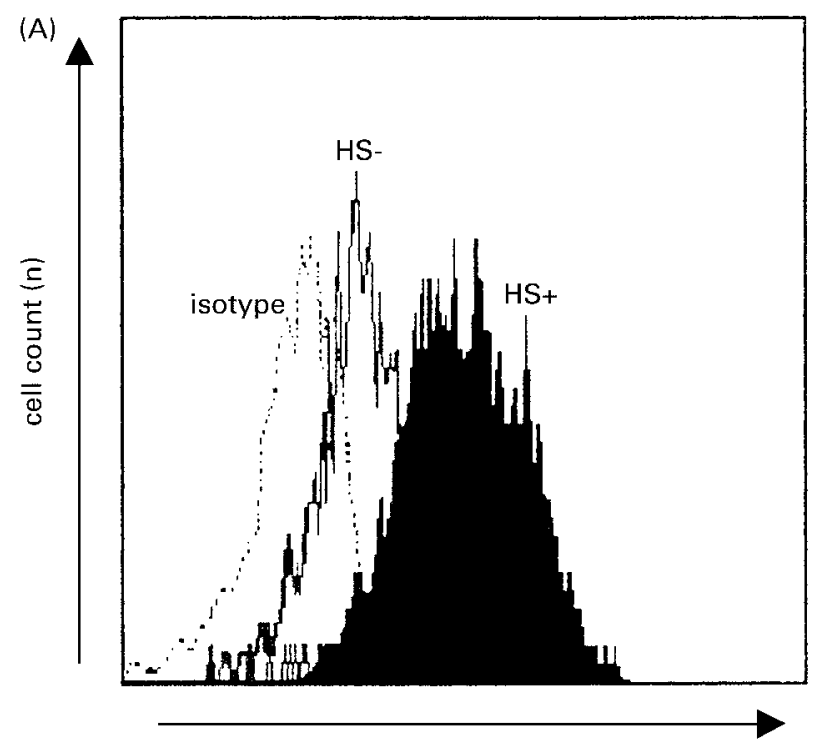

Hsp70 expression (FI)

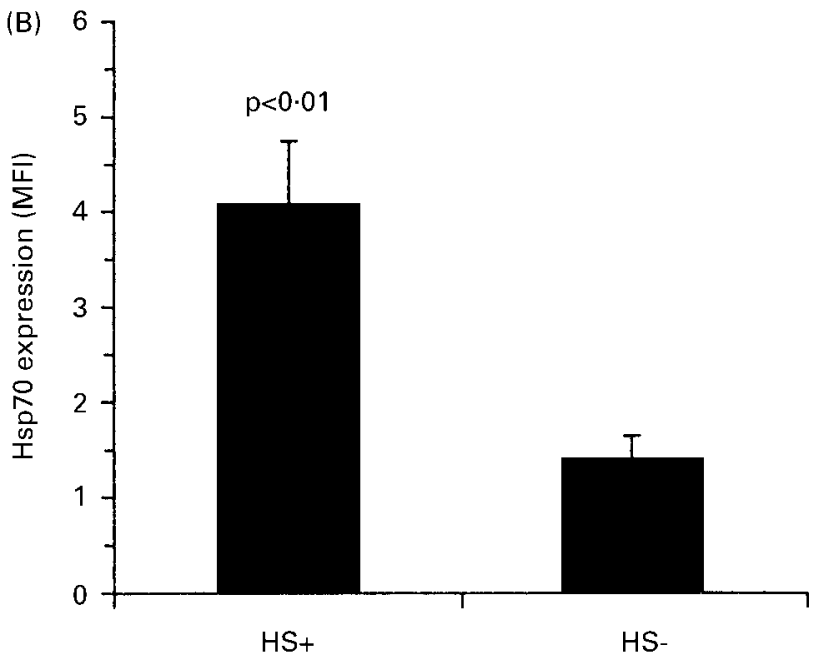

Fig. 1. HSP70 expression of heat-treated and untreated human lymphocytes. Lymphocytes were isolated from whole blood and cultured for $72 \mathrm{~h}$ at $37^{\circ} \mathrm{C}$. Then cells were exposed for $2 \mathrm{~h}$ to $42^{\circ} \mathrm{C}$ $\mathrm{HS}+$ or $37^{\circ} \mathrm{C} \mathrm{HS}-$ and returned to $37^{\circ} \mathrm{C}$ for an additional $3 \mathrm{~h}$. Intracellular HSP70 expression was determined by flow cytometry. (A) Histogram: HSP70 levels are expressed as fluorescence intensity $[\mathrm{FI}]$. The dotted line represents the fluorescence of cells stained with isotype control antibodies. The other peaks represent the fluorescence of heat shocked HS+ and untreated HS- lymphocytes stained with HSP70 specific antibodies. (B) Statistical evaluation: the HSP70 expression was calculated by subtracting the mean fluorescence intensity of cells stained with isotype control antibodies from the mean fluorescence intensity of cells stained with HSP70 specific antibodies. The mean of four independent experiments is indicated. The error bars represent standard deviations. The $P$-value was calculated by Student's $t$-test.
After heat treatment, HSP70 levels increased at all Gln concentrations, but to a different extent (Fig. 2B). At Gln concentrations similar to the plasma levels of healthy subjects $(500 \mu \mathrm{M})$ the HSP70 induction was slightly reduced $(-15 \%)$ in comparison to complete medium
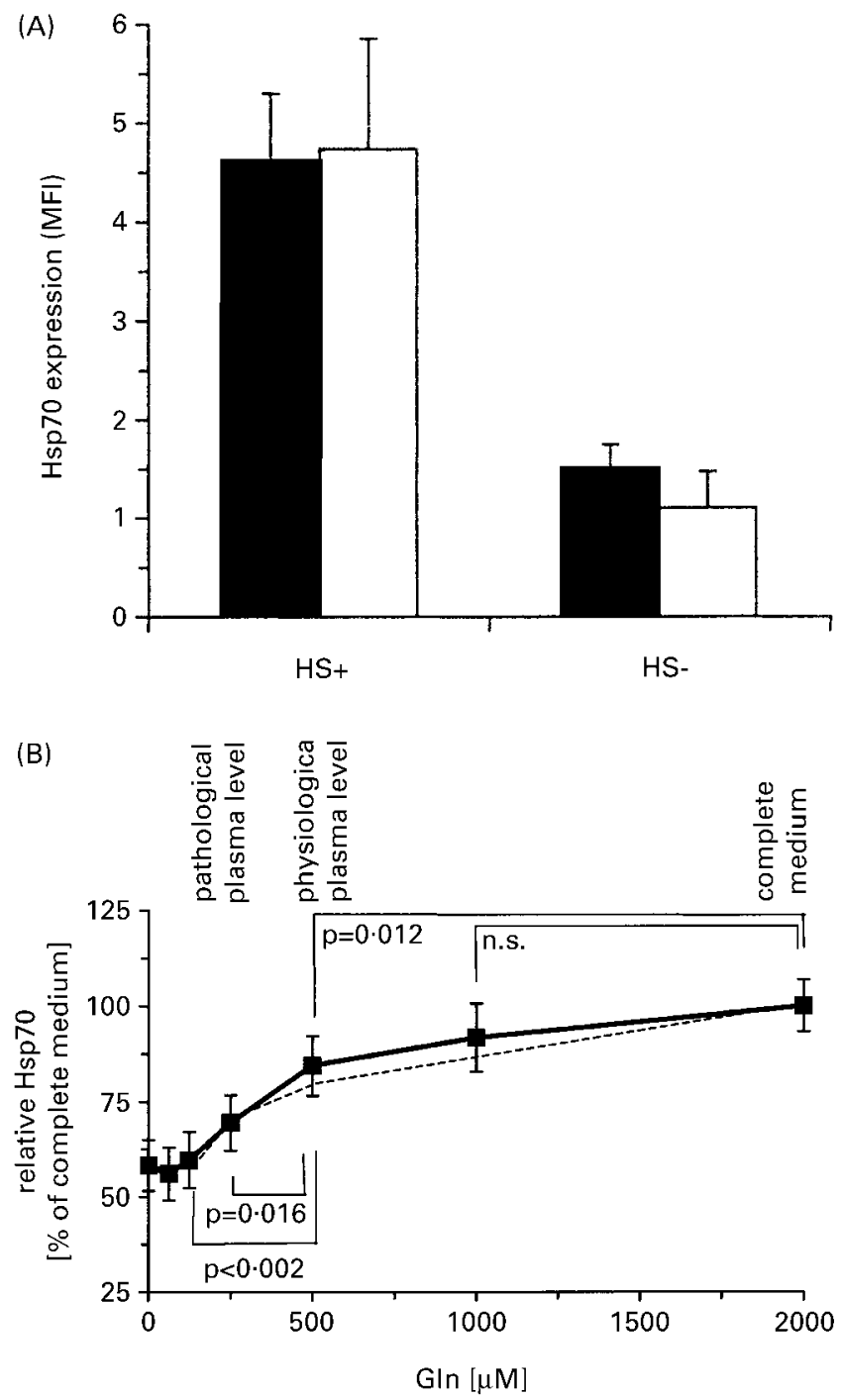

Fig. 2. Influence of $\mathrm{Gln}$ on HSP70 expression. (A) HSP70 expression after long-term Gln-depletion. Lymphocytes were isolated from whole blood and cultured for $72 \mathrm{~h}$ at $37^{\circ} \mathrm{C}$ in the absence of Gln, Gln depleted ( $\square$ ) or in complete medium non depleted ( $\square$ ). Then cells were suspended in complete medium, exposed to heat shock $2 \mathrm{~h}$ at $42^{\circ} \mathrm{C}$ and allowed to recover at $37^{\circ} \mathrm{C}$ for $3 \mathrm{~h}$. HSP70 expression was determined by flow cytometry. The values shown represent the mean $n=3$ and standard deviations are indicated by error bars. (B) HSP70 expression of lymphocytes exposed to various Gln concentrations during heat shock. Lymphocytes were isolated from whole blood and cultured for $72 \mathrm{~h}$ at $37^{\circ} \mathrm{C}$ in the absence of GIn dotted line or in complete medium traced line. Then cells were suspended in medium containing $0,62.5,125,250,500$, or $1000 \mu \mathrm{M}$ Gln or complete medium containing $2000 \mu \mathrm{M}$ GIn, exposed to heat shock $42^{\circ} \mathrm{C}$ for $2 \mathrm{~h}$ and allowed to recover for $3 \mathrm{~h}$ at $37^{\circ} \mathrm{C}$. HSP70 expression was determined by flow cytometry and expressed as the percentage of the HSP70 levels of cells grown and heat-treated in complete medium. The error bars represent standard deviations $n=4$. The $P$-values refer to the non-starved cells and were calculated by Student's $t$-test. 
(2000 $\mu \mathrm{M})$. However, when Gln was reduced to levels seen in plasma of critically ill patients $(250-125 \mu \mathrm{M})$ the HSP70 expression was greatly decreased (about $-40 \%$ ). Repeating the same experiment with Gln-depleted lymphocytes (cultured for $72 \mathrm{~h}$ in the absence of Gln) gave essentially the same results (Fig. 2B dotted line).

Taken together these data clearly show that heat shock mediated HSP70 expression in human lymphocytes depends on the amount of Gln available during the stress response. The Gln concentration prior to heat shock, however, has no effect on HSP70 induction. Since the Gln-dependency of HSP70 induction occurs in the range between physiological and pathological plasma Gln concentrations this effect is of clinical relevance.

\section{Glutamine effect on HSP70 expression induction is not dependent on the proliferative state of lymphocytes}

In the course of an immune response lymphocytes become activated and start to proliferate for elimination of foreign antigens. The experiments described above show that Gln is essential for stress-mediated HSP70 expression in resting lymphocytes. To investigate the effect of Gln on the cellular stress response in activated lymphocytes we stimulated isolated cells with phytohemagglutinin (PHA). This stimulation resulted in a strong proliferation, as shown by $\left[{ }^{3} \mathrm{H}\right]$ thymidine incorporation (Fig. 3A). We suspended activated lymphocytes grown in complete medium for $72 \mathrm{~h}$ in medium with varying Gln concentration $(0,62 \cdot 5,125$, 250,500 , or $2000 \mu \mathrm{M}$ GIn) and exposed them to heat shock. Then cells were allowed to recover for $3 \mathrm{~h}$ at $37^{\circ} \mathrm{C}$ and HSP70 expression was measured. Cells incubated under the same conditions but without PHA-stimulation were used as control. As shown in Fig. 3B, results were comparable in proliferating and non-proliferating lymphocytes. Lymphocytes heat-treated in the presence of $0-250 \mu \mathrm{M}$ Gln showed a reduced HSP70 expression as compared to cells heat treated in medium containing $500 \mu \mathrm{M}$ Gln or complete medium. Thus, the Gln-dependence of heat-mediated HSP70 induction occurs in activated as well as in resting human lymphocytes.

\section{Discussion}

This study shows that Gln depletion leads to an impaired stress response in human lymphocytes. When Gln is reduced from levels observed in plasma of healthy subjects to levels observed in plasma of critically ill patients, lymphocytes express lower amounts of HSP70 in response to heat stress. Gln is known to induce HSP70 expression in several animal cell lines including Chinese hamster ovary cells (Cai et al. 1991), rat intestinal crypt cells (Musch et al. 1998; Wischmeyer et al. 1997), opossum kidney cells (Nissim et al. 1993) and in rat intestinal IEC-6 cells (Ehrenfried et al. 1995). In these studies cells were incubated in medium with extremely high Gln concentrations (from 4 to $20 \mathrm{mM}$ ) which led either to an induction of HSP70 or to a further increase of HSP70 expression after heat stress. These Gln concentrations are far above the physiological plasma Gln concentrations $(0.5-0.6 \mathrm{mmol} / \mathrm{l})$. In contrast the present study investigates the effect of Gln depletion on HSP70 expression. We used human peripheral blood lymphocytes as a model system, because lymphocytes play a central role in the immune response and are exposed to all alterations of blood Gln levels. We found a rather low constitutive HSP70 expression in these cells. This is in accordance with mRNA data that show that HSP70 mRNA is barely detectable in unstressed human lymphocytes (Fincato et al. 1991). Heat treatment at $42^{\circ} \mathrm{C}$, a temperature which is reached during a
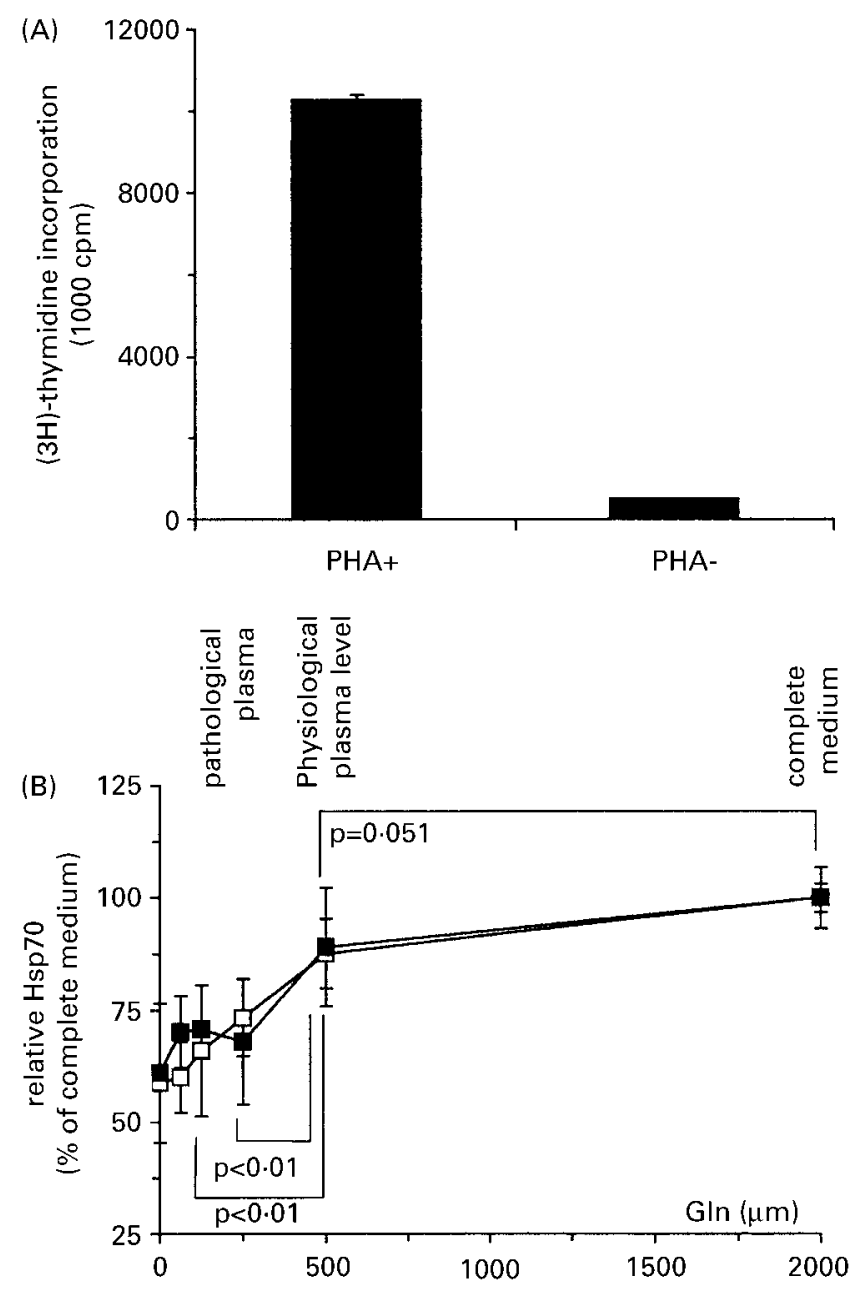

Fig. 3. Heat-induced HSP70 expression in proliferating and nonproliferating human lymphocytes. Lymphocytes were isolated from whole blood and cultured for $72 \mathrm{~h}$ at $37^{\circ} \mathrm{C}$ in complete medium containing $5 \mu \mathrm{g} / \mathrm{ml}$ phytohemagglutinin $\mathrm{PHA}+$ or not PHA-. (A) Proliferation rate. $1 \mu \mathrm{Ci}\left[{ }^{3} \mathrm{H}\right]$-thymidine was added to $\mathrm{PHA}$ treated and non-PHA treated lymphocytes and cells were cultured for an additional $6 \mathrm{~h}$. $\left[{ }^{3} \mathrm{H}\right]$-thymidine incorporation was determined by scintillation counting and used as a measure for lymphocyte proliferation. Results are given as the mean of three independent experiments and the error bars indicate standard deviations. (B) Heat-induced HSP70 expression. PHA treated proliferating and non-PHA treated non proliferating cells were suspended in medium containing $0,62.5,125,250$, or $500 \mu \mathrm{M}$ Gln or in complete medium containing $2000 \mu \mathrm{M}$ Gln, exposed to heat shock $42^{\circ} \mathrm{C}$ for $2 \mathrm{~h}$ and allowed to recover for $3 \mathrm{~h}$ at $37^{\circ} \mathrm{C}$. HSP70 expression was determined by flow cytometry and is expressed as percentage of the HSP70 level in cells grown and heat-treated in complete medium. Results are given as the mean of three independent experiments and the error bars indicate standard deviations. The $P$-values refer to the activated cells $(\boldsymbol{\square})$ and were calculated by Student's $t$-test. ( $\square$ ) refers to resting cells. 
high fever, led to a 3-fold increase in HSP70 expression. A similar induction of HSP70 in heat stressed human lymphocytes was recently reported by others (Dressel \& Gunther, 1999). We could show that this HSP70 induction is strongly impaired when the Gln concentration in the medium is reduced. The strongest effect of Gln deprivation was observed between $125 \mu \mathrm{M}$ and $500 \mu \mathrm{M}$ Gln (see Fig. 2B). At $125 \mu \mathrm{M}$ HSP70 expression is essentially as low as without Gln, whereas at $500 \mu \mathrm{M}$ Gln HSP70 levels are nearly the same as in complete medium. This indicates that the stress response in human lymphocytes is well adapted to the physiological plasma Gln levels $(500-600 \mu \mathrm{M})$ and is impaired when Gln is reduced, as it happens during critical illness. Support for this view comes from a study previously published by our laboratory (Weingartmann et al. 1999). We investigated the HSP70 expression in leucocytes of polytrauma patients with reduced plasma Gln levels. Their leucocytes showed decreased HSP70 expression when compared to healthy controls. In the current study we show that the Gln concentration during the stress response is crucial for HSP70 expression. Gln-starvation prior to stress response has no influence. This suggests that Gln depletion interferes directly in the stress response cascade. The molecular mechanism of this Gln effect has to be investigated in further studies.

Our study shows that HSP70 expression is impaired at subphysiological Gln levels, similar to those observed in critically ill patients. Since HSP70 is a known cytoprotective protein, these results indicate that these immune cells are more susceptible to cytotoxic inflammatory mediators such as reactive oxygen species in the course of such diseases. Supplementation with Gln would help to overcome this effect and thus improve the immune response. This is a new aspect of the immunomodulatory effects of nutritional Gln supplementation.

\section{Acknowledgements}

We are grateful to Christine Brostjan and Susanne Oehler for helpful discussions and proofreading the manuscript. This study was supported by the 'Jubilaeumsfonds der Oesterreichischen Nationalbank’ (No.8311).

\section{References}

Bachelet M, Mariéthoz E, Banzet N, Souil E, Pinot F, Polla C, Durand P, Bouchaert I \& Polla B (1998) Flow cytometry is a rapid and reliable method for evaluating heat shock protein 70 expression in human monocytes. Cell Stress \& Chaperones 3, $168-176$.

Cai JW, Hughes CS, Shen JW \& Subjeck JR (1991) Induction of heat-shock proteins by glutamine. The 'feeding effect'. FEBS-Letters 288, 229-232.

Coligan JE, Kruisbeek AM, Margulies DH, Shevach EM \& Strober W (1996) Current protocols in immunology. In Current Protocols, [R Cioco, editor]. New York, NY: John Wiley and Sons Inc.

Dressel R \& Gunther E (1999) Heat-induced expression of MHC-linked HSP70 genes in lymphocytes varies at the single-cell level. Journal of Cellular Biochemistry 72, 558-569.
Ehrenfried JA, Chen J, Li J \& Evers BM (1995) Glutaminemediated regulation of heat shock protein expression in intestinal cells. Surgery 118, 352-356; discussion 356-357.

Fincato G, Polentarutti N, Sica A, Mantovani A \& Colotta F (1991) Expression of a heat-inducible gene of the HSP70 family in human myelomonocytic cells: regulation by bacterial products and cytokines. Blood 77, 579-586.

Musch MW, Hayden D, Sugi K, Straus D \& Chang EB (1998) Cellspecific induction of HSP72-mediated protection by glutamine against oxidant injury in IEC18 cells. Proceedings of the Association of American Physicians 110, 136-139.

Neu J, Shenoy V \& Chakrabarti R (1996) Glutamine nutrition and metabolism: where do we go from here? FASEB Journal 10, 829-837.

Nissim I, States B, Hardy M, Pleasure J \& Nissim I (1993) Effect of glutamine on heat-shock-induced mRNA and stress proteins. Journal of Cellular Physiology 157, 313-318.

Petronini PG, Urbani S, Alfieri R, Borghetti AF \& Guidotti GG (1996) Cell susceptibility to apoptosis by glutamine deprivation and rescue: survival and apoptotic death in cultured lymphomaleukemia cell lines. Journal of Cellular Physiology 169, $175-185$.

Polla BS \& Cossarizza A (1996) Stress proteins in inflammation. In Stress-Inducible Cellular Responses, pp. 375-391 [U Feige, R Morimoto, I Yahara and B Polla, editors]. Basel: Birkhäuser Verlag.

Ribeiro SP, Villar J, Downey GP, Edelson JD \& Slutsky AS (1994) Sodium arsenite induces heat shock protein-72 kilodalton expression in the lungs and protects rats against sepsis [see comments]. Critical Care Medicine 22, 922-929.

Spittler A, Oehler R, Goetzinger P, Holzer S, Reissner CM, Leutmezer F, Rath V, Wrba F, Fuegger R, Boltz Nitulescu G \& Roth E (1997) Low glutamine concentrations induce phenotypical and functional differentiation of U937 myelomonocytic cells. Journal of Nutrition 127, 2151-2157.

Spittler A, Winkler S, Götzinger P, Oehler R, Willheim M, Tempfer C, Weigel G, Függer R, Boltz Nitulescu G \& Roth E (1995) Influence of glutamine on the phenotype and function of human monocytes. Blood 86, 1564-1569.

Suzuki K, Sawa Y, Kaneda Y, Ichikawa H, Shirakura R \& Matsuda $\mathrm{H}$ (1997) In vivo gene transfection with heat shock protein 70 enhances myocardial tolerance to ishemic-reperfusion injury in rat. Journal of Clinical Investigation 99, 1645-1650.

Szondy Z \& Newsholme EA (1991) The effect of time and addition of glutamine or nucleosides on proliferation of rat cervical lymphnode T-lymphocytes after stimulation with concavalin A. Biochemical Journal 278, 471-474.

Villar J, Edelson JD, Post M, Mullen JB \& Slutsky AS (1993) Induction of heat stress proteins is associated with decreased mortality in an animal model of acute lung injury. American Review of Respiratory Diseases 147, 177-181.

Villar J, Ribeiro SP, Mullen JB, Kuliszewski M, Post M \& Slutsky AS (1994) Induction of the heat shock response reduces mortality rate and organ damage in a sepsis-induced acute lung injury model [see comments]. Critical Care Medicine 6, 914-921.

Weingartmann G, Oehler R, Derkits S, Oismuller C, Fugger R \& Roth E (1999) HSP70 expression in granulocytes and lymphocytes of patients with polytrauma: comparison with plasma glutamine. Clinical Nutrition 18, 121-124.

Welch WJ (1991) The role of heat-shock proteins as molecular chaperones. Current Opinion in Cell Biology 6, 1033-1038.

Wischmeyer PE, Musch MW, Madonna MB, Thisted R \& Chang EB (1997) Glutamine protects intestinal epithelial cells: role of inducible HSP70. American Journal of Physiology 272, G879-884. 